\title{
Diretrizes e modelo conceitual de custos para o setor público a partir da experiência no governo federal do Brasil*
}

\author{
Nelson Machado** \\ Victor Branco de Holanda***
}

SumÁrio: 1. Introdução e aspectos gerais; 2 . Visão esquemática geral do modelo e suas principais características; 3 . Correspondência dos conceitos de contabilidade governamental aos de custos; 4. Relacionamento entre políticas públicas, recursos, atividades e objetos de custo; 5 . Sistema de acumulação e método de custeio no setor público; 6. Custos no setor público e os sistemas de informação de governo; 7. Considerações finais e conclusão.

Summary: 1. Introduction and general aspects; 2. Schematic overview of the model and its main features; 3. Correlation between the concepts of government accounting and costs; 4 . The relationship between public policies, funds, activities and cost objects; 5 . Accumulation system and costing method in the public sector; 6. Costs in the public sector and government information systems; 7. Final remarks and conclusion.

Palavras-chave: custos no setor público; estrutura conceitual de custos para o setor público; sistemas de informações de custos; métodos de custeio e sistema de acumulação de custos no setor público.

KEY WORDS: costs in the public sector; conceptual framework of costs for the public sector; cost information systems; costing methods and cost accumulation system in the public sector.

\footnotetext{
* Artigo recebido em fev. e aceito em maio 2010.

** Doutor em contabilidade e controladoria pela Faculdade de Economia, Administração e Contabilidade da Universidade de São Paulo (FEA/USP). Secretário executivo do Ministério da Fazenda. Endereço: Ministério da Fazenda, Esplanada dos Ministérios, Edifício Sede, $4^{\circ}$ andar, Gabinete Brasília - CEP 70.048- 900, Brasília, DF, Brasil. E-mail: nelson.machado@fazenda.gov.br.

*** Doutor em contabilidade e controladoria pela Faculdade de Economia, Administração e Contabilidade da Universidade de São Paulo (FEA/USP). Professor da Universidade Federal do Rio Grande do Norte (UFRN). Diretor de gestão estratégica do Ministério da Fazenda. Endereço: Ministério da Fazenda, Esplanada dos Ministérios, Edifício Sede, 4ª andar, Gabinete Brasília CEP 70048-900, Brasília, DF, Brasil. E-mail: victorbholanda@gmail.com.
} 
Este artigo apresenta o Sistema de Informação de Custos do Governo Federal, descrevendo o modelo e suas principais características, desde o conceito até a finalidade e os grupos de usuários, explorando a correspondência entre os conceitos de contabilidade governamental e de custos. O artigo demonstra o relacionamento entre as políticas públicas, recursos, atividades e objetos de custo. Para tanto, remete aos conceitos de sistema de acumulação e método de custeio de custos no setor público, correlacionando-os aos sistemas de informação governamentais. O artigo também apresenta o modelo téorico-conceitual, as diretrizes que sustentaram a sua concepção e a descrição do seu processo de implantação que ainda está em curso. O artigo finalmente olha para o futuro, depois de vencida a etapa de implantação do sistema, e exorta os leitores a se inserirem no debate sobre mensuração de custos. A importância do SIC é enfatizada como elemento de melhoria da qualidade do gasto no setor público.

Guidelines and conceptual model of costs for the public sector based on the Brazilian federal government's experience

This article presents the Cost Information System (CIS) of the Brazilian federal government. It describes the taxonomic model and its main features, from its concepts to its purposes and user groups, and explores the correlation between the concepts of governmental accounting and cost accounting. It demonstrates the relationship between public policies, fund management, activities and cost objects. To this end, it uses the concepts of accumulation system, costing method and costs in the public sector, as well as government information systems. The article also presents the theoretic conceptual model and the guidelines of the design, and describes the implementation process, which is still ongoing. It finally looks into the future after the development stage of the CIS, and urges its readers to dive into the debate about measuring costs. The importance of CIS to improve the quality of spending in the public sector is highlighted.

\section{Introdução e aspectos gerais}

A introdução de uma nova abordagem de gestão pública que prioriza a mensuração de custos no governo federal integra uma das etapas essenciais para a transformação de paradigmas atualmente existentes sobre o papel e importância do setor público como agente propulsor de geração de eficiência no uso de recursos públicos e também escassos. Os administradores do setor público necessitam de um conjunto de informações gerenciais para cumprir com eficiência, eficácia e efetividade as políticas públicas. Dessa forma, impõe-se a necessidade de um sistema de informação de custos capaz de auxiliar decisões típicas, tais como comprar ou alugar, produzir internamente ou terceirizar determinado serviço ou atividade. Ou, ainda, permitir comparações entre os custos de atividades ou serviços iguais produzidos por unidades organizacionais diferentes, objetivando conhecer e estimular a melhoria do desempenho de 
seus dirigentes. Além disso, as informações de custos associadas aos benefícios das políticas públicas deveriam ser a base para a formulação da proposta orçamentária, sendo o orçamento o fio condutor que permite executar as despesas e prestar os serviços públicos planejados.

Não se pretende, neste artigo, fazer exaustivas citações nem delineamento da abordagem metodológica, já que as mesmas foram realizadas nos trabalhos teóricos de Machado (2005) e Holanda (2002) que - entre outros estudos - serviram de base para a "experimentação" aqui relatada. Antes de ser um viés científico, para os autores é um reforço à abordagem em ciência social e à utilização da pesquisa-ação, desenhado com auxílio de técnicas de estudo de caso comparativo com abordagem participante por vários anos de observação direta. A pesquisa-ação consiste num ciclo de análise, "fato-achado", concepção, planejamento, execução e mais "fato-achado" ou avaliação. E então, uma repetição desse círculo inteiro de atividades, realmente uma espiral de tais círculos. As intervenções são uma manipulação experimental e a resolução do problema é a meta; por consequência seu valor científico deve ser medido proporcionalmente ao resultado e pela transformação da realidade alcançada.

\section{Visão esquemática geral do modelo e suas principais características}

Não obstante as determinações legais, o fato é que a administração pública até 2010 (seja o Executivo, Legislativo ou Judiciário) não utilizava sistema de custos, salvo por iniciativas isoladas de alguns órgãos. O motivo é porque, até então, não havia nem sistema, nem metodologia adequada capaz de ser aplicada sistematicamente e uniformemente para toda a administração pública federal.

Para suprir essa lacuna, em outubro de 2008 foi realizada a oficina de trabalho "Sistemas de custos na administração pública: modelo conceitual e estratégia de implementação". No evento, o Ministério da Fazenda foi ratificado como órgão responsável para coordenar a tarefa de conceber e implantar o Sistema de Informação de Custos do Governo Federal, por meio da utilização de dados dos diversos sistemas estruturantes do governo federal.

Por consequência da decisão acima referida, a partir de outubro de 2008, o sistema de custos passou a ter um projeto executivo. Pode-se dizer que a partir de então o assunto deixou de ser, para os órgãos centrais do governo federal, uma intenção (vontade), saindo da esfera da discussão das ideias para 
ser um processo estruturado com responsáveis, concepção teórica definida, cronograma e recursos. Estes últimos acontecimentos foram determinantes para que em março de 2010 o governo federal, por meio da Secretaria do Tesouro Nacional e o Serpro, sob coordenação da Secretaria Executiva do Ministério da Fazenda, finalmente homologasse o Sistema de Informação de Custos do Governo Federal (SIC).

Para facilitar a exposição de algumas escolhas conceituais específicas do modelo adotado no governo federal é apresentada a figura 1, que retrata a visão esquemática geral do modelo do SIC.

\section{Figura 1}

\section{Visão geral do modelo}

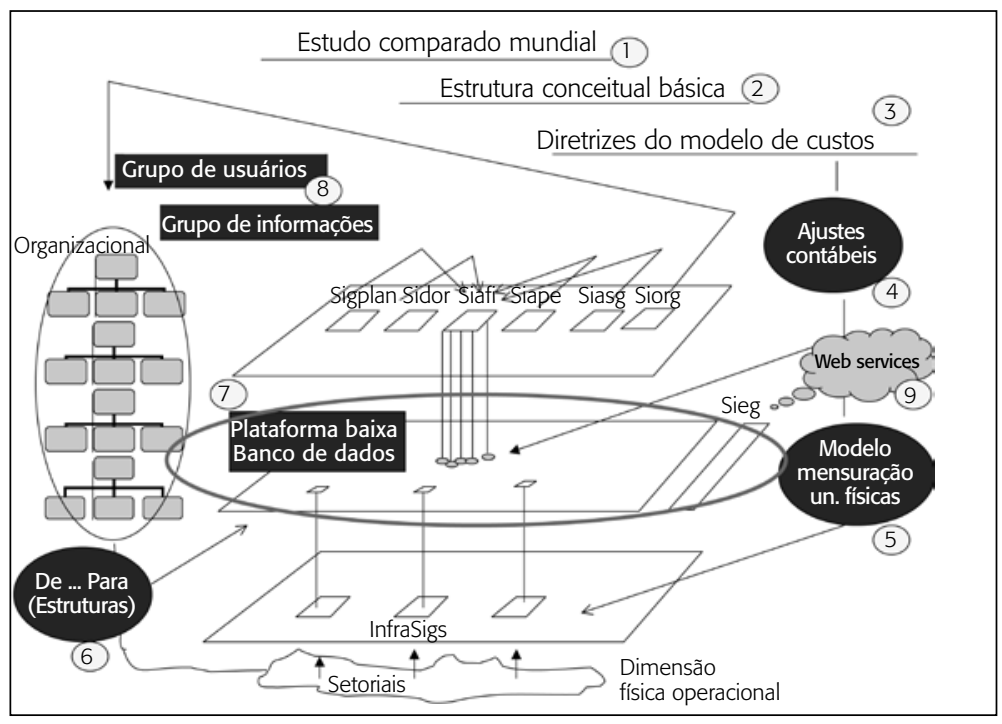

Fonte: Holanda et al. (2010:83).

Os itens de " 1 " a "9", mais o "10" prototipação, "11" implantação, "12" treinamento, e "13" abordagem de mudança cultural, formam o conjunto de componentes de todo o projeto do SIC do governo federal. Parte da descrição desses componentes será realizada no decorrer deste trabalho, outros como o estudo comparado das experiências internacionais e algumas reflexões sobre a estrutura conceitual serão objeto de outros artigos. Além de apresentar o modelo e os componentes, a figura 1 será útil para diferenciar alguns itens importantes do modelo, por exemplo, a diferença da modelagem por pilotos versus a sistêmica e concomitante. 


\section{Diferença da modelagem por "pilotos" versus a "sistêmica e concomitante"}

Neste tópico, é necessário primeiro enfatizar que um sistema de informação de custos concebido para toda a administração pública federal para os três poderes deve garantir o atributo da comparabilidade, mas deve também permitir a possibilidade de detalhamento das informações em razão das diferentes expectativas e necessidades informacionais das diversas unidades organizacionais e seus respectivos usuários. O sistema deve ser capaz de produzir informações em diferentes níveis de detalhamento, mediante a geração de diferentes relatórios, sem perder o atributo da comparabilidade já mencionada. As informações mais agregadas devem ser geradas pelo sistema disponibilizado pelo órgão central, porém as mais analíticas precisam ser geradas nos sistemas de informações gerenciais de cada órgão setorial a partir da informação agregada, ou seja, elas devem ser conciliáveis. Feito o destaque da dimensão e abrangência de um sistema de custos para toda a administração pública federal, pode-se então entrar na especificidade da diferenciação dos modelos como proposto nesta seção.

Após as diversas contribuições e tentativas de implantação de um sistema de custos para o governo federal, o problema central ainda persistia: qual modelo adotar, como construir e implantar? Em resumo, como "fazer acontecer"? Havia lacunas conceituais importantes e, principalmente, divergências no entendimento dos atributos flexibilidade e gradualismo quando aplicados ao modelo de custos. O modelo de gradualismo e flexibilidade anteriormente defendido consistia primeiro na construção de vários pilotos em diversas unidades distintas da administração pública federal e só depois a modelagem geral de um sistema de custos. Essa abordagem foi modificada e uma nova proposta então foi desenhada enfatizando as discussões tratadas nos trabalhos teóricos já referenciados.

Um ponto importante que acabou viabilizando a concepção e posteriormente a implantação do SIC foi a abordagem em duas dimensões concomitantes: uma macro, sistêmica, generalizante e outra micro, específica, particular, que respeita a especificidade física operacional de cada órgão ou entidade. $\mathrm{Na}$ visão do modelo geral, pela sua característica de encontro, foi denominada "rodoviária", devido à característica básica fundamental de juntar as duas dimensões, os dois "mundos". De um lado, o processo dedutivo de alocação dos gastos aos objetos de custos a partir da visão dos órgãos centrais; do outro, o processo indutivo do particular para o geral, das necessidades físico-operacionais dos órgãos setoriais finalísticos (saúde, educação, segurança, infraestrutura etc.). 
A primeira etapa do modelo: a dedutiva — dos órgãos centrais via sistemas estruturantes para a rodoviária - tem a vantagem de gerar uma informação de custos sintética, porém perfeitamente comparável para toda a administração pública federal. Este requisito torna o SIC único e bastante útil para avaliar desempenho e resultado das políticas públicas pelos órgãos centrais do governo federal. Na segunda fase do processo (indutivo: do particular para o geral), o sistema permite ajustes a cada realidade física operacional. Nesta fase, cada unidade administrativa pode aperfeiçoar a sua informação específica recebida já ajustada para custos, disponibilizada de forma uniforme, consistente e verificável, referenciada a objetos de custos comuns e padronizada para toda a administração pública. Conforme mencionado, este requisito fundamental torna viável a análise de desempenho e resultado das políticas públicas pelos órgãos centrais do governo federal.

Destaca-se que este é o conceito de gradualismo que foi adotado, ou seja, a concepção de um modelo geral ( $1^{\circ}$ nível: dedutivo, até a rodoviária) concomitante à abordagem específica ( $2^{\circ}$ nível: indutivo, da rodoviária para baixo) e não à abordagem de primeiro a construção de pilotos e depois o modelo geral. Em síntese, no lugar de "primeiro" pilotos e "depois" modelo geral optou-se por "concomitante, tudo isso junto", conforme a abordagem teórica e sistêmica advinda dos trabalhos teóricos já mencionados.

\section{Definição, finalidades e usuários do sistema de informação de custos no setor público}

O Sistema de Informações de Custos do Governo Federal (SIC) é um sistema de apoio à gestão, a ser utilizado tanto pelos órgãos executores das políticas públicas quanto pelos órgãos centrais de planejamento e de controle. O sistema de custo não é mais um sistema operacional de administração financeira ou que virá a substituir os sistemas contábeis atuais. Os sistemas de custos não possuem caráter transacional e sim gerencial, estabelecendo relações voltadas para os objetos de custo, a partir de informações de outros sistemas auxiliares.

\section{Principais finalidades do Sistema de Informação de Custos do Governo Federal}

As principais finalidades do Sistema de Informação de Custos do Governo Federal são: 
- maior eficiência do processo alocativo - permite avaliar se determinados bens ou serviços produzidos pelo governo justificam os custos correspondentes, ou se há alternativas a custos menos elevados, contribuindo as informações de custo para que os órgãos de planejamento e orçamento avaliem as alternativas, em geral no decorrer do processo de decisão, quanto à alocação dos recursos públicos (caráter ex ante);

v maior eficiência operacional - a produção de bens e serviços pelo Estado deve se submeter a algumas avaliações, quanto às maneiras diferentes de produzir o mesmo produto com custos menores, que permitam identificar ineficiências operacionais e oportunidades de redução de gastos; quanto à avaliação do desempenho das pessoas e organizações (inclusive outros entes e ONGs); quanto à identificação de economias com despesas correntes (CF, art. 39, §7으) e também quanto ao custo/benefícios das ações. A análise comparativa das diversas maneiras de realizar o mesmo produto com custos menores. Assim, facilita a identificação de ineficiências e oportunidades de redução de gastos; avaliação de resultado e desempenho, bem como benchmarking e identificação de atividades de baixo valor agregado;

- fixação de preços públicos e taxas - para cálculo do preço de venda em organizações governamentais que fornecem bens ou serviços mediante pagamento, o conhecimento do custo dos produtos é essencial para que se estabeleça o preço justo a ser cobrado ou se conheça o resultado financeiro obtido, lucro ou prejuízo.

Outras finalidades podem ainda ser destacadas, tais como subsidiar o processo de planejamento e orçamentação; apoiar as decisões sobre continuar responsável pela produção de determinado bem, serviço ou atividade, ou entregá-lo a entidades externas; possibilitar a melhoria das informações internas gerenciais para possibilitar a medição de resultados e desempenhos e proporcionar controles mais orientados a resultados. A par de todas as possibilidades, o maior desafio é fazer com que as informações geradas sejam úteis e apropriadas ao processo decisório, essencialmente para facilitar a tarefa do gestor na busca por maximizar os resultados dos recursos públicos para a sociedade da qual ele faz parte.

\section{Grupos de usuários do Sistema de Informação de Custos do Governo Federal}

O sucesso da implantação do Sistema de Informação de Custos do Governo Federal pelas entidades públicas não depende apenas da exigência legal nem 
do rebuscamento de sua estrutura conceitual. Mesmo sendo importantes esses fatores, é fundamental que os usuários percebam a utilidade da informação de custos para controle e melhoramento gerencial de suas atividades e aperfeiçoamento do processo de decisão. A seguir, estão relacionados os principais usuários do Sistema de Informação de Custos do Governo Federal:

- Secretaria do Tesouro Nacional (STN) - órgão central do sistema de contabilidade federal, responsável pelo desenvolvimento e implantação do Sistema de Informação de Custos do Governo Federal;

- Secretaria de Orçamento Federal (SOF/MF) — coordena o processo de alocação de recursos públicos federais no âmbito do sistema federal de planejamento e orçamento e administra o Sidor;

v secretarias-executivas (Secex) - responsáveis por assistir os ministros de Estado na supervisão e coordenação estratégica das atividades dos órgãos integrantes da estrutura de cada ministério e das entidades a ele vinculadas;

v subsecretarias de Planejamento, Orçamento e Administração (Spoas) órgãos setoriais incumbidos da operacionalização dos sistemas de planejamento e de orçamento federal, de administração financeira federal, de contabilidade federal, de pessoal civil da administração federal, de administração dos recursos de informação e informática, de serviços gerais e nacional de arquivos, no âmbito de cada órgão/entidade;

- Secretaria de Planejamento e Investimentos Estratégicos (SPI/MF) - coordena o setor de planejamento do Sistema Federal de Planejamento e Orçamento e gerencia o Plano Plurianual e o SIGPlan;

- Sistema de Gestão do Plano Plurianual - reúne conjunto de atores responsáveis em diferentes níveis pela aplicação dos recursos públicos e a gestão de programas, ações e projetos no âmbito de cada órgão/entidade pública federal. No modelo atual tem-se gerente de programa, gerente executivo, coordenador de ação, coordenador executivo e unidade de monitoramento e avaliação;

v ordenadores de despesas ${ }^{1}$ - responsáveis pela autorização de despesas no âmbito dos órgãos e entidades públicas federais;

\footnotetext{
${ }^{1}$ Alocado, eventualmente, nas posições mencionadas anteriormente.
} 
- Controladoria-Geral da União (CGU) ${ }^{2}$ - responsável por avaliar a ação governamental, a gestão dos administradores públicos federais e a aplicação de recursos públicos por entidades de direito privado, por intermédio da fiscalização contábil, financeira, orçamentária, operacional e patrimonial;

- Tribunal de Contas da União (TCU) - auxilia o Congresso Nacional no controle externo, por meio do exercício da fiscalização contábil, financeira, orçamentária, operacional e patrimonial da União e das entidades da administração direta e indireta, quanto à legalidade, à legitimidade e à economicidade e a fiscalização da aplicação das subvenções e da renúncia de receitas;

- sociedade - pesquisadores, analistas especializados e o cidadão de forma geral, responsável pelo controle social dos gastos públicos.

Para compreensão da percepção da utilidade e da necessidade da informação de custos na perspectiva dos usuários do governo federal, bem como outras questões importantes para a modelagem do sistema, foi elaborada uma pesquisa em toda a administração pública federal. A pesquisa foi instrumentalizada por questionário e a análise resumida dos dados foi apresentada no I Seminário Internacional de Informação de Custos (Esaf/DF) e está disponível no site: <www.socialiris.org/custosnosetorpublico>.

\section{Pressupostos básicos e características da informação de custos}

A geração de informações de custos pressupõe a adoção do regime de competência. Enquanto a contabilidade governamental não adotar na sua plenitude o regime de competência serão necessários os "ajustes contábeis", conforme componente 4 do modelo geral (figura 1). Já as características qualitativas da informação de custos podem ser resumidamente conceituadas como atributos essenciais para que a informação seja adequada. Elas podem ser (sem a

\footnotetext{
${ }^{2}$ Sistema de Controle Interno do Poder Executivo Federal, intergrado por: I - Controladoria-Geral da União, como órgão central, incumbido da orientação normativa e da supervisão técnica dos órgãos que compõem o sistema; II - as secretarias de Controle Interno (Cisets) da Casa Civil, da Advocacia-Geral da União, do Ministério das Relações Exteriores e do Ministério da Defesa, como órgãos setoriais; e III - as unidades de controle interno dos comandos militares, como unidades setoriais da Secretaria de Controle Interno do Ministério da Defesa.
} 
pretensão de exaustão) assim elencadas: compreensibilidade, tempestividade, comparabilidade, granularidade, confiabilidade.

\section{Correspondência dos conceitos de contabilidade governamental aos de custos}

Para que seja possível o uso das informações da contabilidade governamental na construção de um sistema de custos, é necessária uma aproximação terminológica e conceitual entre a contabilidade governamental e a de custos. Ao analisar a terminologia da contabilidade de custos, destacam-se os seguintes conceitos (Martins, 2003:25):

> gasto - "sacrifício financeiro com que a entidade arca para a obtenção de um produto ou serviço qualquer, sacrifício esse representado por entrega ou promessa de entrega de ativos";

จ investimentos - "gasto ativado em função de sua vida útil ou de benefícios atribuíveis a futuros períodos";

- custo - "gasto relativo a bem ou serviço utilizado na produção de outros bens ou serviços";

จ despesa - "bem ou serviço consumido direta ou indiretamente para obtenção de receitas";

\ desembolso — "pagamento resultante da aquisição do bem ou serviço".

Esses conceitos podem ser pensados como um ciclo: o equipamento (ativo) usado no processo produtivo, que foi gasto e se transformou em investimento e posteriormente considerado parcialmente como custo torna-se uma despesa do período no processo de apuração do resultado. É claro, também, que o gasto pode se transformar imediatamente em despesa ou custo sem passar pela fase do investimento. O mais frequente é que o gasto se distribua em investimentos, custo e despesa, exceto em caso específico, quando caracterizado como "perda" por corresponderem a reduções do patrimônio que não proporcionaram nenhum recebimento compensatório ou geraram produtos e/ou serviços.

A figura 2 mostra esse relacionamento e destaca o fato de que ainda hoje são observadas algumas dificuldades na aplicação desses conceitos no processo de análise dos gastos no setor público. 
Figura 2

Visão geral da correspondência dos conceitos entre a contabilidade governamental e a de custos

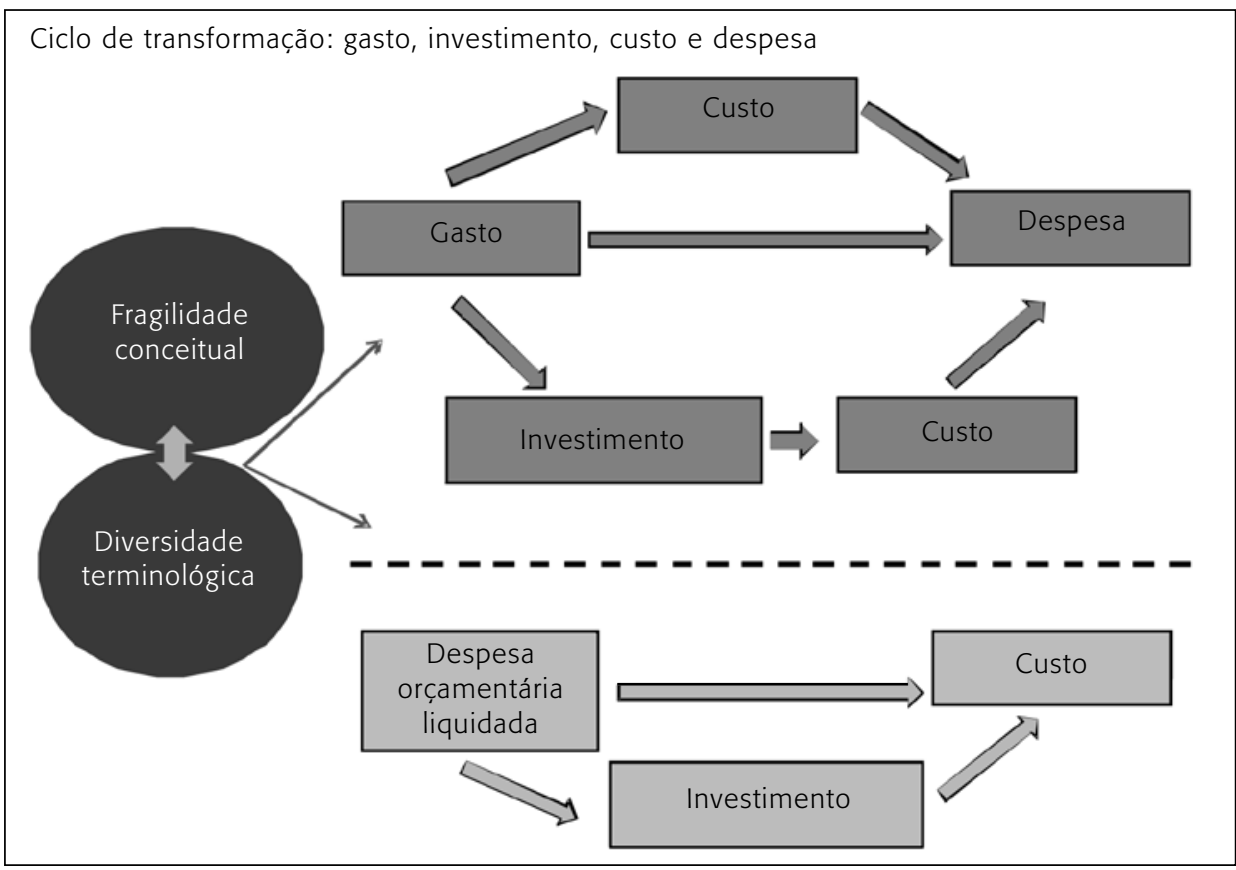

No âmbito da contabilidade empresarial, é importante destacar a distinção entre custo e despesa. Objetivando apurar custo para efeito de avaliação de estoques, a contabilidade de custos tradicional tem colocado uma fronteira relativamente simples entre esses dois conceitos, ou seja, todos os gastos ocorridos no produto, até que ele fique pronto para a venda, são custos de produção. A partir desse ponto, os gastos são considerados despesas. Assim, os gastos com comercialização são considerados despesas e vão impactar o resultado do período. Por outro lado, no setor público, as despesas orçamentárias têm um ciclo próprio, passando pelas fases de fixação, empenho, liquidação e pagamento.

\section{Paralelo entre o setor empresarial e o público}

Traçando um paralelo entre o mundo empresarial e o público, percebem-se algumas semelhanças ou correspondências entre os conceitos. A fase da fixação, 
em termos genéricos, pode ser compreendida e praticada da mesma forma que o estabelecimento do custo-padrão, uma vez que o custo-padrão não deixa de ser uma espécie de orçamento. A fase do empenho não encontra correspondência nos conceitos normalmente utilizados pela contabilidade de custos.

Já na fase de liquidação, são essencialmente verificados os critérios de realização da despesa e os valores "liquidados" significam que o direito de receber do credor foi analisado, bem como atestado que este cumpriu sua obrigação contratual. A fase do pagamento, obviamente, é idêntica ao conceito de desembolso, observando-se apenas que, na contabilidade pública o pagamento deve ser precedido normalmente por todas as fases anteriores, enquanto na contabilidade empresarial o desembolso pode ser feito antes, durante ou após a entrada da utilidade comprada, portanto, defasada ou não do gasto.

O quadro 1 mostra o resumo dessa correspondência terminológica.

$$
\text { Quadro } 1
$$

Contabilidade governamental x contabilidade de custos: correspondência terminológica

\begin{tabular}{|ll|}
\hline Contabilidade governamental & Contabilidade de custos empresarial \\
\hline Fixação & Padrão \\
Empenho & Não é tradicionalmente usado \\
Liquidação & Gasto (realizado) \\
Pagamento & Desembolso \\
\hline
\end{tabular}

Fonte: Machado (2002).

Assumindo, então, que os conceitos de "gastos" e valores "liquidados" se equivalem, pode-se tomar a despesa orçamentária liquidada como ponto de partida para a construção do sistema de informação de custos. As despesas orçamentárias liquidadas serão custos quando relativas a bens ou serviços utilizados e consumidos no exercício corrente, e investimento quando beneficiarem exercícios futuros. Os investimentos da mesma forma que no setor privado transformam-se posteriormente em custos. A figura 2 na parte abaixo da linha tracejada mostra esse relacionamento.

Pode-se então afirmar que no setor público, dado o atual modelo de contabilização dos gastos governamentais, a despesa liquidada é a variável a partir da qual deveremos realizar os ajustes conceituais necessários para se chegar à informação de custos. Assim, no setor público, o conceito de des- 
pesa liquidada funciona como elo conceitual e metodológico para apuração dos custos.

É importante salientar que, no setor público, diferentemente do privado, não há a necessidade de se distinguir entre o custo dos produtos e serviços e a despesa do período. Essa separação é muito importante quando o objetivo da apuração do custo é a avaliação de estoque dos produtos que serão vendidos no período seguinte. No setor público, essa distinção é irrelevante (relativizada), já que o objetivo é apurar o custo dos serviços públicos prestados no período e o pressuposto é a inexistência de estoques de serviços ou produtos em processamento e/ou acabados, fato para a grande maioria do setor público.

A identificação dos investimentos a partir das despesas liquidadas é relativamente simples. A classificação das despesas orçamentárias por categorias econômicas ${ }^{3}$ estabelece desde logo a distinção entre as despesas correntes e as despesas de capital, estando os investimentos destacados dentro das despesas de capital.

Já a identificação dos custos a partir das despesas liquidadas pode ser feita utilizando-se as despesas classificadas como custeio. Assumindo que o objetivo das entidades públicas seja produzir bens e serviços para entregá-los à comunidade e que a análise dos custos é feita dentro de períodos anuais, a primeira aproximação com a contabilidade governamental leva a afirmar que todos os gastos ou valores "liquidados", classificados como despesas de custeio, são custos de algum bem ou serviço produzido pela entidade governamental nesse período. No entanto, para que essa afirmação seja verdadeira são necessários os ajustes conceituais contábeis.

\section{Ajustes conceituais contábeis}

O modelo de custos ora proposto traz intrinsecamente a necessidade de promover uma integração entre os sistemas orçamentário, contábil e o de informação de custos. Integração esta possível, na realidade atual, somente por intermédio do sistema contábil e das classificações da despesa orçamentária. No caso dos serviços públicos prestados pelo Estado não resta dúvida de que a informação da despesa liquidada é a que mais se aproxima da definição de

\footnotetext{
${ }^{3}$ A classificação econômica da despesa tem as seguintes categorias: despesas correntes - despesa de custeio e transferências correntes. Despesas de capital — investimentos, inversões financeiras, transferências de capital.
} 
custo como o gasto realizado na aquisição de bens ou serviços necessários à produção de outros bens ou serviços.

Nos valores liquidados, há parcelas que necessitam de tratamento especial para se tornar adequadas ao conceito de custo dos produtos e serviços do período, esta é a definição dos ajustes a partir da contabilidade governamental para a contabilidade de custos aqui tratada. Alguns exemplos destes ajustes são: liquidação forçada, compra de materiais para estoques e despesas de exercícios anteriores.

Os gastos com obras de conservação e adaptação de bens imóveis podem beneficiar mais de um período e, portanto, são investimentos, mas, como estão classificados como despesas de custeio, é necessário reclassificá-los para não distorcer os custos dos serviços prestados no período.

Os gastos com pessoal do quadro da entidade, mesmo quando aplicados em investimento, estarão sempre classificados no grupo das despesas correntes. Portanto, é necessário identificá-los e reclassificá-los.

A liquidação forçada é registrada no encerramento do exercício, tendo como contrapartida a conta "restos a pagar não processados". Seu objetivo é levar todas as despesas legalmente empenhadas a comporem as despesas do exercício financeiro (art. 35 da Lei no 4.320). Há duas causas básicas geradoras da liquidação forçada: ${ }^{4}$ a primeira é quando os serviços foram prestados. São, portanto, custos do período, mas não há documentação hábil para se processar a liquidação normal. Exemplos dessa situação são os fornecimentos de água, luz e telefone relativos ao mês de dezembro. Nesse caso, como a liquidação forçada é feita por estimativa, é necessário observar o valor efetivamente pago no início do exercício seguinte. Se o valor pago é menor que o da liquidação forçada, então ocorrerá o cancelamento de uma parcela dos restos a pagar não processados, devendo essa parcela ser utilizada para o ajuste dos custos dos fornecimentos em análise. Se o valor a ser pago for maior que o montante da liquidação forçada, será necessário fazer novo empenho utilizando-se a dotação relativa às despesas de exercícios anteriores. A segunda se refere a fornecimentos de materiais de consumo em trânsito; como a mercadoria não chegou, obviamente não pode ser consumida. Logo, não é custo do período. Nesse caso, o tratamento mais adequado seria considerar todas as compras em

\footnotetext{
${ }^{4} \mathrm{~A}$ liquidação forçada das obras em andamento não é tratada aqui porque não interfere na apuração dos custos dos serviços do período. Além disso, também não tem impacto na ativação das obras quando concluídas, já que isto é feito após a última medição e pelo valor acumulado ao longo de todo o contrato.
} 
andamento como materiais para estoque, não impactando, portanto, os custos do período como pode ser visto no próximo item.

Nas compras de materiais de consumo, devem ser discriminadas as de consumo imediato das que transitam pelo almoxarifado, constituindo, portanto, estoque durante algum período. As compras para consumo imediato não oferecem maiores dificuldades: uma vez liquidadas, são gastos que se transformam imediatamente em custos. Por outro lado, como material de consumo em estoque (almoxarifado) faz parte do ativo permanente, a contabilidade governamental dá a ele um tratamento especial. No momento da liquidação é feito, normalmente, no sistema financeiro, o lançamento - despesa orçamentária a despesa orçamentária a pagar. Entretanto, esse evento vai impactar também o sistema patrimonial, em que no ato da liquidação é lançado - almoxarifado a mutações patrimoniais ativas (aquisição de bens para o almoxarifado) e, no momento do consumo, o lançamento é mutações patrimoniais passivas (baixa de bens móveis por consumo) a almoxarifado. Dessa forma, o saldo da conta almoxarifado mostrará, no balanço patrimonial, a existência de material de consumo, ao passo que a conta "baixa de bens móveis por consumo", do grupo "variações patrimoniais", mostrará os materiais utilizados no período. Logo, o ajuste, nesse caso, é simples: basta substituir o montante das compras de materiais para estoque do grupo das despesas orçamentárias pelo valor dos materiais efetivamente consumidos registrados na conta "baixa de bens móveis por consumo".

\section{Consolidação e visão esquemática dos ajustes conceituais contábeis}

Assim, o surgimento da informação de custos se dá a partir da realização de ajustes sobre a informação inicial obtida do Siafi. Os ajustes contábeis foram efetuados em duas etapas. O ajuste inicial consistiu na identificação e carregamento de informações baseadas em contas contábeis que trazem a informação orçamentária e não orçamentária, ajustando-se por acréscimo os valores patrimoniais e por exclusão os valores orçamentários que não são custos do período, conforme conceitos de contabilidade de custos.

A segunda etapa do ajuste consistiu na exclusão de informações que estivessem nas contas citadas acima, mas que não compunham a informação de custo. Este ajuste utilizou parâmetros gerenciais dispostos nas contas correntes das contas contábeis inseridas na primeira etapa. Da modelagem conceitual advinda da reflexão teórica explicitada chegou-se à repercussão 
prática no SIC. Numa tentativa de visão de síntese, é apresentada no quadro 2 a modelagem dos ajustes conceituais contábeis já com efeito nos sistemas de informações e sua modelagem para aplicação.

Quadro 2

Modelagem dos ajustes conceituais

\begin{tabular}{|ll|}
\hline Despesa orçamentária executada & \\
\hline & $\begin{array}{l}\text { Despesa liquidada } \\
\text { Despesa executada por inscrição de restos a pagar } \\
\text { não processados. }\end{array}$ \\
\hline Ajustes da despesa orçamentária & $\begin{array}{l}\text { Despesa executada por inscrição de restos a pagar } \\
\text { não processados }\end{array}$ \\
\hline$(-)$ & $\begin{array}{l}\text { Restos a pagar não processados liquidados no } \\
\text { exercício }\end{array}$ \\
& Despesas de exercícios anteriores \\
& Formação de estoques \\
$(-)$ & Concessão de adiantamentos \\
$(-)$ & Despesas de capital não efetivas \\
\hline$(-)$ & Depreciação/amortização/exaustão \\
\hline$(+)$ & Consumo de estoque \\
\hline Ajustes patrimoniais & Despesa incorrida de adiantamentos \\
\hline$(+)$ & \\
\hline
\end{tabular}

Fonte: Coordenação-geral de Contabilidade da União, Secretaria do Tesouro Nacional, adaptado de Machado (2002).

A necessidade de ajuste reflete em grande parte a atual fragilidade da contabilidade, ainda muito influenciada pelo controle do orçamento em detrimento do controle do patrimônio. 


\section{Despesas de exercícios anteriores}

No setor público, a legislação reconhece a possibilidade de ocorrerem situações em que despesas relativas a exercícios anteriores possam ser empenhadas, liquidadas e pagas no exercício corrente. ${ }^{5}$ Essas despesas são escrituradas em contas claramente segregadas e devem ser expurgadas, caso o objetivo seja apurar o custo dos serviços do exercício.

Por último, é necessário ter presente que existem "custos do período" que não estão incluídos nos gastos ou "valores liquidados", classificados como despesas de custeio, já que não fazem parte do sistema orçamentário, tais como a depreciação do ativo permanente e provisões de encargos trabalhistas como, por exemplo, as licenças remuneradas. É necessário que essas informações sejam registradas no sistema patrimonial da contabilidade governamental e incorporadas ao custo dos serviços prestados, inclusive como determina as atuais normas de contabilidade aplicadas ao setor público.

\section{Relacionamento entre políticas públicas, recursos, atividades e objetos de custo}

O relacionamento direto entre as políticas públicas, recursos, atividades e objetos de custos pode ser visto na figura 3. Esse quadro mostra sinteticamente que a definição das políticas públicas é o principal determinante dos custos do setor público, derivando daí os programas e as ações, bem como a identificação dos recursos necessários para executá-los. Os recursos estimados e consumidos são acumulados diretamente nos projetos ou atividades. A partir dos custos acumulados por projeto ou atividade, por um processo de agregação, é possível encontrar os custos das funções e dos centros de responsabilidade. Os custos unitários dos produtos ou serviços derivam da relação entre os custos das atividades e as quantidades físicas executadas.

Alguns questionamentos podem ser feitos a essa proposta. O primeiro é que os custos apurados dessa forma podem conter distorções, "sendo a mais significativa a falta de critérios rigorosos na vinculação do pessoal aos projetos e atividades em que realmente atua". Todavia, é importante salientar que a qualidade das informações do sistema integrado de custos depende, fundamentalmente, do rigor com que na fase do orçamento são associados os

\footnotetext{
${ }^{5}$ Ver art. 37 da Lei no ${ }^{4} .320 / 64$.
} 
recursos com as atividades/projetos e, posteriormente, na fase da execução, depende do esmero do lançamento contábil utilizando-se as classificações corretas para cada transação.

Figura 3

Relacionamento: políticas públicas, recursos, atividades e objetos de custo

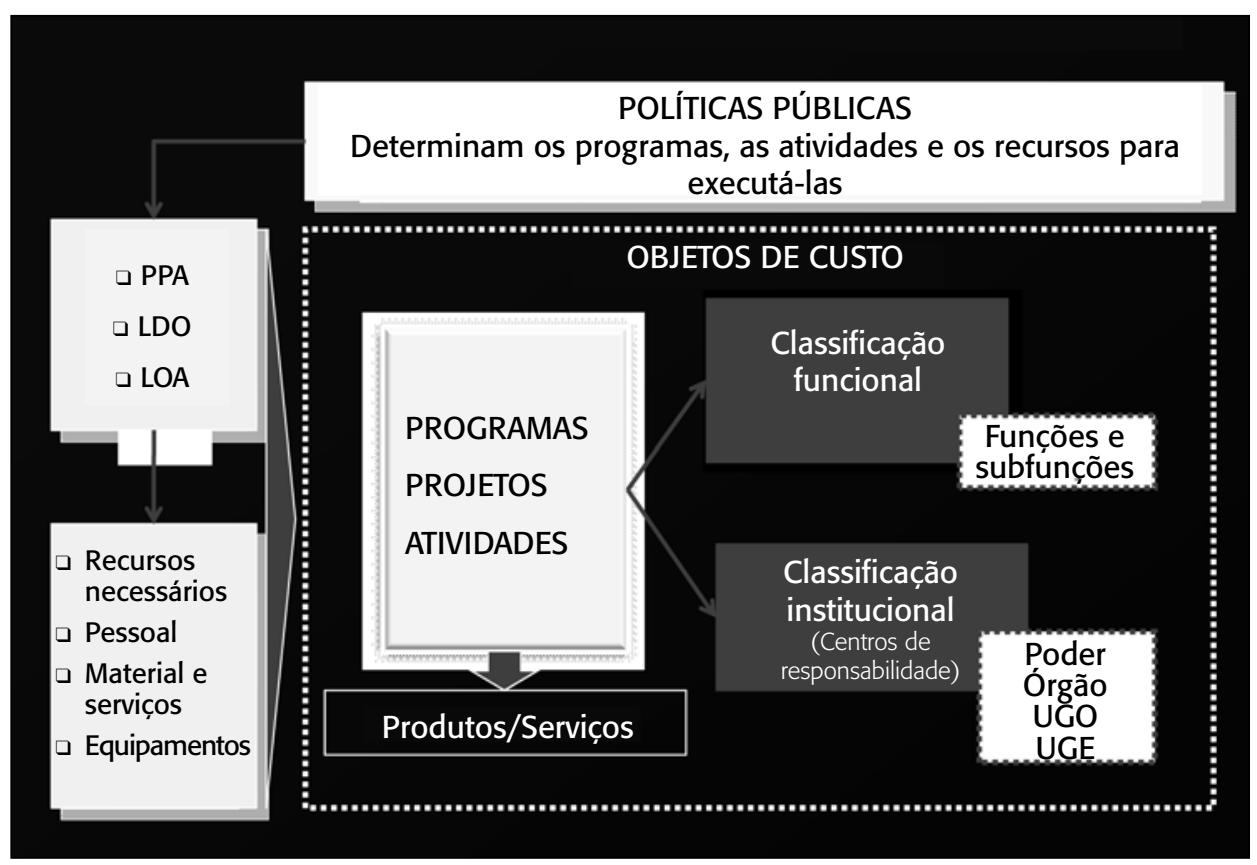

Fonte: Holanda et al. (2010:39).

Além disso, a melhor garantia do aperfeiçoamento do sistema de custos são o cálculo e a divulgação dos custos unitários dos bens e serviços entregues à população, pois eles forçarão os gestores envolvidos a analisar as informações, buscando, de um lado, corrigir as distorções de classificação e, de outro, tornar mais eficiente o uso dos recursos. Vale ressaltar que apurar custos deve ser um processo de contínuo aprendizado e aperfeiçoamento, a informação vai sendo gerada e quando usada e anlisada funciona como feedback, retroalimentando todo o processo. Vale também a máxima: "isto é igual a andar de bicicleta", ou seja, é melhor um "pouco" de teoria e ir para a prática e depois ir melhorando o modelo e as informações, do que um modelo ideal apenas no 
papel. Essa filosofia foi fundamental para que, em março de 2010, o SIC fosse homologado e posteriormente disponibilizado para uso.

O segundo questionamento é que as atividades e projetos são excessivamente genéricos ou globais, não permitindo uma associação direta dos recursos consumidos com os seus produtos. Aqui é necessário ter presente a diversidade das ações governamentais. Há casos em que a atividade, mesmo genérica, tem um único produto final, entregue aos cidadãos ou usuários do serviço público. Nesse caso, a apropriação do custo ao produto dá-se diretamente sem maiores problemas. Quando houver mais de um produto resultante de uma mesma atividade, pode-se entre outras técnicas tratá-lo como produção conjunta. Isto é, indicar o custo total da atividade e as quantidades produzidas de cada um dos produtos diferentes. A eficiência do gestor seria analisada a partir da comparação do efetivamente produzido com o padrão ou o orçado.

Por outro lado, não se pode olvidar que o rol dos projetos e atividades é prerrogativa de cada um dos entes públicos; dessa forma, é possível criar um dicionário de atividades mais genéricas ou mais específicas de acordo com as necessidades de informação. Apesar disso, seguramente, haverá atividades cujos produtos serão de difícil explicitação, enumeração e quantificação; nesse caso, obviamente, haverá dificuldades no cálculo do custo unitário, qualquer que seja o método de custeio adotado.

Esta multiplicidade e a complexidade mencionadas foram abordadas conceitual e metodologicamente de forma adequada, resultando na modelagem do SIC em dois níveis. Cabe ainda ressaltar algumas das principais características conceituais aplicadas ao SIC.

\section{Sistema de acumulação e método de custeio no setor público}

Nesta seção estão segregados os conceitos de sistema de acumulação e método de custeio e sua aplicabilidade no setor público.

\section{Sistema de acumulação de custos do setor público}

Serviços típicos do setor público como ensino, assistência médica, distribuição da justiça, cuidado com a segurança pública e a defesa nacional, entre outros, são prestados de forma contínua, requerendo, portanto, um sistema de acumulação de custos por processo. Isto significa que os custos desses serviços 
devem ser acumulados durante um determinado período - mês, trimestre, semestre - , sendo o custo unitário desses serviços apurado pela comparação entre o custo do período e as unidades produzidas no mesmo período. No final do período contábil, todas as contas que acumulam custos devem ser encerradas.

Por outro lado, o setor público também cria capacidade para prestar serviço quando constrói uma escola, um hospital, uma ponte, um conjunto habitacional, uma estrada. Esse tipo de atuação se caracteriza como encomenda específica, com data inicial e final de execução, significando, portanto, que o sistema de acumulação de custos requerido neste caso é o sistema por "ordem de serviço". Os custos relativos a essa obra devem ser acumulados nessa ordem até que a obra termine, quando então será apurado o custo total da ordem ou custos unitários, quando for o caso. Ressalte-se que o término do período contábil não encerra a ordem; os custos relativos à ordem em andamento devem ser ativados como obras em andamento ou título assemelhado.

Tendo presente a conceituação de projeto e atividade no setor público, pode-se concluir que o custo do projeto deve ser acumulado por ordem, e o custo da atividade, acumulado por processo.

\section{Sistema de custeio do setor público}

O sistema de custeio do setor público assenta-se nos custos histórico e orçado. $\mathrm{O}$ custo histórico é elemento fundamental na integração entre o sistema de custos e os sistemas de orçamento e contabilidade pública. Por sua vez, o custo orçado poderá basear-se em simples estimativas ou utilizar a ferramenta do custo-padrão. O ideal é que se construíssem padrões para todas as atividades e produtos a serem executados pelo setor público; no entanto, isso não é praticável no início do processo de implantação de custos, mas um ideal a ser perseguido. É importante, todavia, que o sistema de informação de custo crie condições de especificar, no custo orçado, quando se trata de padrão ou de mera estimativa.

\section{Método de custeio do setor público}

A escolha do método de custeio do setor público não é tarefa fácil, na medida em que há defensores para quase todos os métodos. Além disso, no setor público, diferentemente do setor privado, não há limitação legal quanto ao 
uso dos métodos de custeio. Nesse sentido, qualquer um dos cinco métodos (custeio pleno, por absorção, por atividades, variável e custeio direto) pode ser adotado.

\section{Método de custeio direto no setor público}

O primeiro argumento, em defesa do custeio direto, é que esse método, por não conter qualquer tipo de rateio, permite analisar o desempenho dos gestores e das políticas públicas com maior objetividade e sem as intermináveis discussões a respeito dos custos gerais transferidos. E facilitar a análise de resultado e desempenho é o objetivo central do sistema integrado de custos.

O segundo argumento é que esse método está entranhado no sistema de planejamento, orçamento e contabilização da execução orçamentária, o que facilita a implantação do sistema integrado de custos.

Esse fato pode ser demonstrado da seguinte forma:

v a ação do governo - projetos e atividades — é a categoria utilizada para a programação das despesas orçamentárias;

v os recursos necessários à execução dessas ações, classificados conforme sua natureza econômica, são estimados e detalhados por projetos e atividades. Dessa forma, os recursos a serem consumidos associam-se diretamente com as atividades a serem executadas;

v a ação de governo se desenvolve em um determinado espaço organizacional perfeitamente identificável sendo, portanto, possível acumular diretamente as despesas executadas por atividades/projetos, por órgãos, por gerentes de programas ou ordenadores de despesas. Como os projetos/atividades devem cumprir uma função de governo, são também facilmente identificáveis com a classificação funcional;

- o modelo de acumulação direta das despesas orçamentárias pode ser transformado em modelo de acumulação do custo do período ou da ordem, uma vez feitos os ajustes das despesas orçamentárias liquidadas e dos investimentos (principalmente consumo dos estoques), conforme se discutiu anteriormente nos ajustes conceituais contábeis.

O terceiro argumento é que a relação custo-benefício da informação, embora difícil de ser quantificada, é claramente favorável ao método do custeio direto, uma vez que sua implantação pode ser feita muito rapidamente e 
com baixo custo de treinamento, já que para os funcionários e gestores esse método soa familiar.

Vale destacar que a proposta do SIC é adotar como método de custeio o custeio direto até a plataforma intermediária (rodoviária), conceituado aqui como o método que aloca todos os custos ${ }^{6}$ - fixos e variáveis - diretamente a todos os objetos de custo sem qualquer tipo de rateio ou apropriação. E da rodoviária para baixo (figura 1), deve-se respeitar a diversidade e a realidade físico-operacional de cada unidade considerada.

A escolha do custeio direto até a "rodoviária" (figura 1) garante a comparabilidade e está corroborada na literatura, já que quanto maior a complexidade nos esquemas de alocação, maiores os erros de classificação e mensuração induzidos. Assim, o modelo geral proposto garante a possibilidade de comparação, sem perder de vista a customização. Esta é a maior virtude do modelo: conviver com as duas necessidades.

\section{Custeio por atividades no setor público}

Outro questionamento possível é que o método de custeio direto proposto não incorpora os avanços da gestão por atividades. Essa ferramenta de gestão preocupa-se, fundamentalmente, com a capacidade não utilizada e com as atividades que não agregam valor, buscando reduzir os desperdícios e eliminar as atividades desnecessárias. À primeira vista, não haveria maiores dificuldades em adotar o custeio por atividades no setor público, já que:

v toda ação governamental é decomposta em atividades/projetos. As atividades/ projetos são o elemento-chave nos sistemas de orçamento e de contabilidade;

v o conceito de atividade do setor público é muito semelhante ao formulado por Brimson:

Conceito legal — um instrumento de programação para alcançar o objetivo de um programa, envolvendo um conjunto de operações que se realizam de modo contínuo, das quais resulta um produto necessário à manutenção da ação de governo

(Art. 2º, Portaria no ${ }^{\circ}$ 42, de 14 de abril de 1999)

\footnotetext{
${ }^{6}$ Ressalte-se que a contabilidade governamental, normalmente, não registra a depreciação do imobilizado e a amortização das despesas financeiras relativas a débito de longo prazo, conforme discutido em Machado (2002).
} 
Conceito de Brimson (1996:63-64) — atividades são processos que consomem recursos substanciais para gerar uma produção ou ainda um critério básico da contabilidade por atividades é a capacidade de relacionar uma atividade a um produto, processo, projeto ou outro objetivo a reportar do qual a administração necessita informação de custo.

No entanto, é necessário considerar que a adoção do método de custeio por atividades ampliaria as dificuldades para implantação de um sistema geral integrado - custo, orçamento e contabilidade — por diversas razões:

v o processo de implantação exigiria a identificação das atividades relevantes, tempos médios de execução de cada uma delas e número de horas trabalhadas de cada um dos funcionários, entre outros aspectos;

v o treinamento deveria ser intensivo para uniformizar os critérios a serem adotados em todos os órgãos ou centros de custo;

- o período de tempo necessário para que o sistema se estabilizasse e produzisse benefícios seria ampliado enormemente;

- o sistema geraria uma quantidade de informações praticamente impossível de ser analisada pelos órgãos gestores centrais (secretarias de Governo, Planejamento e Fazenda).

Porém, implantado o sistema de custos proposto (custeio direto), nada impede - sendo até desejável - que, sem retrabalho, órgãos específicos, a partir das informações extraídas do sistema de informação contábil-gerencial (até a rodoviária, figura 1), construam modelos específicos (depois da rodoviária, ou seja, dela para baixo) de análise e gerenciamento de seus custos, seguindo quaisquer outros modelos de custeio e apropriação.

Esta adoção (e por consequência, alocação) gradual, separada em dois grandes momentos - macro e micro - , constitui requisito essencial para o modelo de custos integrado à contabilidade, permitindo que a comparabilidade seja feita tomando-se por base os objetos de custos (figura 3) já fortemente utilizados na cultura da gestão brasileira.

Nesse sentido, trabalhando com a ideia de hierarquia de atividades, pode-se assumir que as atividades/projetos correspondem ao conceito de macroatividades, podendo ser decompostas em atividades menores. A partir dos custos acumulados nas atividades/projetos ou nos departamentos, identificamse os direcionadores de consumo dos recursos por essas atividades menores. Em seguida, identificam-se os direcionadores dos custos dessas atividades aos produtos e serviços. No decorrer desse processo, busca-se, também, a identificação da capacidade não usada, possibilitando identificar as atividades que não agregam valor aos produtos ou serviços. 


\section{Custos no setor público e os sistemas de informação de governo}

Sintetizando as diretrizes propostas neste artigo, a figura 4 mostra o relacionamento entre as principais ações do modelo de decisão amplo e o sistema de informação. A figura evidencia, também, a integração do sistema de custos do setor público aos demais sistemas de informações: orçamento e contabilidade.

É interessante observar que o sistema de informação de custo absorve os dados do sistema orçamentário e do sistema contábil. Para tanto, é necessário apenas efetuar os ajustes contábeis, discutidos anteriormente, transformando a despesa em custo. Além dos dados absorvidos desses sistemas, o sistema de informação de custo necessita registrar, apenas, os dados relativos aos produtos e às atividades executadas.

Por último, é destacado o fato de que os objetos de custo, como já dito, são agregados utilizando-se as mesmas regras de acumulação das despesas orçamentárias.

Figura 4

Sistema de Informação de Custos do Governo Federal e os demais sistemas de informação

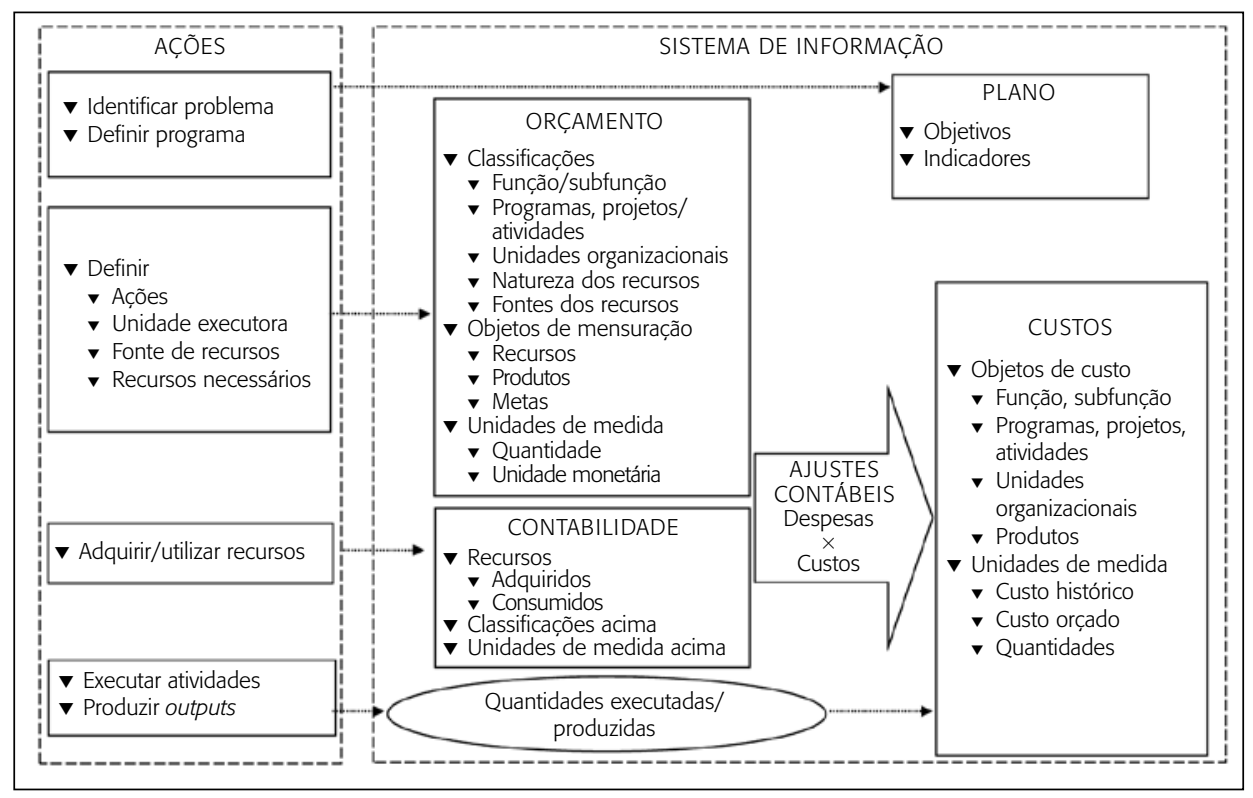

A figura 4 não será descrita em detalhes, pois o objetivo é demonstrar a visão sistêmica que foi priorizada no modelo de concepção e implantação 
do SIC. A figura reforça sob outros aspectos alguns detalhes já evidenciados na figura 1 , principalmente a integração do sistema de custos à contabilidade e ao orçamento, a partir dos ajustes conceituais necessários. Uma descrição mais analítica do modelo completo de integração, abrangendo todo o ciclo, será objeto de outro artigo.

\section{Considerações finais e conclusão}

O Sistema de Informação de Custos do Governo Federal permite a efetiva mensuração de custos sob a ótica administrativa e programática, a partir dos órgãos centrais de planejamento, orçamento, contabilidade e finanças, para atender de forma uniforme todos os órgãos e entidades da estrutura federal. A metodologia de mensuração de custos utilizada convive ainda com as limitações atuais na contabilidade pública, a falta de integração dos sistemas estruturantes e a falta de padronização das estruturas organizacionais do governo federal. Com a adoção da contabilidade patrimonial aplicada à esfera pública, essa metodologia irá "gradativamente se aperfeiçoando".

\section{Reforçando e destacando as principais diretrizes}

Alguns princípios gerais devem ser considerados para definir a trajetória de implementação de um sistema de informações de custos:

v os benefícios propiciados pelas informações devem superar os custos necessários para obtê-las;

- a informação gerada deve ser útil ao processo decisório, o que significa ter poder preditivo, permitindo antecipar, corrigir ou confirmar expectativas;

- as informações devem ser oportunas e confiáveis, ou seja, representar os fatos com fidelidade, neutralidade e de forma verificável;

v as informações devem ser comparáveis no tempo ou entre organizações, serviços, objetos de custo comuns.

Considerando a construção do sistema de custos e sua vinculação com o modelo orçamentário, financeiro e contábil atual e considerando ainda as especificidades do modelo proposto a partir da visão do órgão central, destacam-se os seguintes requisitos gerais: 
v o sistema de informação de custo integra-se conceitual e sistematicamente aos subsistemas: orçamento público, contabilidade governamental e processamento de dados;

v esses subsistemas compõem o sistema de informações contábeis gerenciais do ente público e têm como limite de atuação os dados e informações internas;

- o sistema de orçamento público é o receptáculo das decisões sobre as políticas públicas e o balizador de sua execução;

v as informações dos valores e quantidades orçadas, classificadas sob o prisma institucional, funcional e programático, são o ponto de partida do sistema de informação de custos e, consequentemente, da avaliação dos gestores do ponto de vista da eficiência, eficácia e efetividade;

- as despesas liquidadas orçamentárias equivalem ao conceito de gasto e podem ser consideradas custo dos produtos ou serviços prestados no período após as reclassificações e ajustes conceituais necessários;

$\checkmark$ programa - principal objeto de custo do sistema. Esta diretriz impede a total padronização das contas do sistema de custo;

- o conjunto de objetos de custo é formado por categorias do sistema orçamentário - programática, funcional, institucional, e produtos e serviços prestados, identificados e mensurados no sistema orçamentário;

- sistema de acumulação de custos - projetos por ordem e atividades por processo. A partir do custo dos projetos e das atividades, a acumulação se faz de acordo com a hierarquia das contas do sistema contábil-orçamentário;

v sistema de custeio baseia-se nos custos histórico e orçado;

v método de custeio direto - recomendável até a "rodoviária" e a partir dela de acordo com a realidade física operacional e a maturidade da gestão e dos sistemas de informação necessários para a captura dos dados a serem utilizados.

\section{Uso da informação de custo exige ampliação da maturidade de gestão}

A informação de custos proporciona conteúdo fundamental para subsidiar decisões governamentais de alocação mais eficiente, facilitando a sustentabilidade e o desenvolvimento econômico. A sua instrumentalização exige a 
transparência dos processos e a definição de etapas para a redução das fragilidades oriundas do ciclo de gestão e, consequentemente, das políticas públicas. É necessário aumentar o debate sobre mensuração de custos e destacar sua importância para a melhoria da qualidade do gasto no setor público e qualificar a discussão de perspectivas e desafios na gestão da informação de custos na administração pública.

Num modelo de gestão moderno em bases gerenciais, não se pode (ou melhor, não se deve) tomar decisão sem conhecer as diferentes alternativas de ação, seus custos e seus benefícios. A partir da efetivação do Sistema de Informação de Custos do Governo Federal as condições para a mudança foram efetivamente potencializadas. A simples existência do sistema mostra que uma etapa importante foi vencida, agora é necessário aumentar o debate sobre mensuração de custos e destacar sua importância para a melhoria da qualidade do gasto no setor público, qualificando a discussão das perspectivas e desafios na gestão da informação de custos na administração pública.

\section{Futuros desafios}

Convém ressaltar que governar não é como mexer nos controles de uma máquina e obter resultados previsíveis. Além da definição das áreas de atuação do governo, e suas funções, surgem paralelamente dúvidas quanto à forma de atuação. Questões como: com que recursos, fazer diretamente ou mediante delegação, com que prioridade, são exemplos dessas indagações. Não se deve perder de vista que, no caso brasileiro, o desafio é duplo: a busca da competitividade econômica fomentada por um Estado eficaz e a diminuição das desigualdades sociais. O Estado deve priorizar a universalização das políticas públicas. Isso não é, a nosso ver, contraditório com a eficiência da ação governamental. Como exemplo, podemos citar o desempenho dos bancos públicos, que, mesmo tendo cumprido funções altamente relevantes na retomada do crédito durante a crise econômica mundial, apresentam lucros e resultados muitas vezes superiores aos do setor privado.

Futuramente, a partir dos avanços na contabilidade pública, mediante a adoção do regime de competência, a implantação do sistema de custos permitirá, no médio prazo, o incremento das possibilidades de melhoria da eficiência do gasto governamental brasileiro.

As discussões que tratam de normas gerais (ora denominada "Nova Lei de Finanças públicas", ora "Lei da Qualidade do Gasto - LQF") continuam e se intensificaram em 2010. A referida norma tenta disciplinar várias dire- 
trizes para elaboração do plano, orçamento, contabilidade pública, níveis de endividamento e controle. Vários aspectos voltados para a responsabilidade no processo orçamentário, na gestão financeiro-contábil e patrimonial, visando fortalecer a gestão responsável, estão em curso. Constata-se que, quanto mais madura for a concepção teórica e a discussão em torno desta concepção, mais fácil será levar este consenso para o arcabouço legal. No entanto, vale lembrar, com base em evidenciação empírica, que a mudança não se fará por decreto, será preciso aperfeiçoamento contínuo do arcabouço conceitual e, sobretudo, mudanças de comportamentos.

A par de todas as possibilidades, o maior desafio é fazer com que as informações geradas sejam úteis e apropriadas ao processo decisório.

\section{Referências}

ALBUQUERQUE, Cláudio; MEDEIROS Márcio; FEIJÓ, Paulo Henrique. Gestão de finanças públicas. FEIJÓ, Paulo Henrique (Ed.). 2. ed. Brasília, 2008.

ALONSO, Marcos. Custo no serviço público. Texto para Discussão, n. 31. Brasília: Enap, 1998.

BRASIL. Lei no 4.320/64, de 17 de março de 1964. Estatui normas gerais de direito financeiro para elaboração e controle dos orçamentos e balanços da União, estados, municípios e do Distrito Federal. Diário Oficial da República Federativa do Brasil, Brasília, 23 mar. de 1964.

. Decreto-lei no 200, de 25 de fevereiro de 1967. Dispõe sobre a organização da administração federal, estabelece diretrizes para a Reforma Administrativa e dá outras providências. Diário Oficial da República Federativa do Brasil, 27 fev. 1967, retificado em 8 mar., 30 mar. e 17 jul. 1967.

. Lei Complementar no 101, de 4 de maio de 2000. Estabelece normas de finanças públicas voltadas para a responsabilidade na gestão fiscal e dá outras providências. Diário Oficial da República Federativa do Brasil, Brasília, 5 maio 2000.

. Lei no 10.180, de 6 de fevereiro de 2001. Organiza e disciplina os sistemas de planejamento e de orçamento federal, de administração financeira federal, de contabilidade federal e de controle interno do Poder Executivo Federal, e dá outras providências. Diário Oficial da República Federativa do Brasil, Brasília, 7 fev. de 2001.

BURBIDGE, John L. The principles of production control. London: Macdonald \& Evans Ltd., 1971. 
CRUZ, Flávio da et al. Comentários à Lei no 4.320. 3. ed. São Paulo: Atlas, 2003. GARRISON, Ray H.; NORREN, Eric W. Contabilidade gerencial. Tradução de José Luiz Pavarato. 9. ed. Rio de Janeiro: LTC, 2001.

GIACOMONI, James. Orçamento público. 11. ed. São Paulo: Atlas, 2002.

GONÇALVES, M. A.; ZAC, J. I.; AMORIM, C. A. Gestão estratégica hospitalar: aplicação de custos na saúde. Revista de Administração FACES Journal, v. 8, n. 4, p. 161-179, 2009.

HILL, N. T. Adoption of costing systems in U.S. hospitals: an event history analysis 1980-1990. Journal of Accounting and Public Policy, v. 19, n. 1, p. 41-71, 2001.

HOLANDA, Victor Branco. Controladoria governamental no contexto do governo eletrônico - uma modelagem utilizando o enfoque sistêmico e a pesquisa-ação na Coordenadoria de Controle Interno da Secretaria da Fazenda do Estado de São Paulo, 2002.

; LATTMAN-WELTMAN, Fernando; GUIMARÃES, Fabrícia (Orgs.). Sistema de informação de custos na administração pública federal: uma política de Estado. Rio de Janeiro: FGV, 2010.

HORNGREEN, Chalers T. et al. Contabilidade de custos. 9. ed. Rio de Janeiro: LTC, 2000.

IFAC (International Federation of Accountants). Public Sector Committee. Perspectives on cost accounting for government. Study 12. New York, 2000. Disponível em: <www.ifac.org>. Acesso em: 13 mar. 2010.

KOHAMA, Heilio. Contabilidade pública: teoria e prática. 9. ed. São Paulo: Atlas, 2003.

KRAVCHUK, R. S.; SCHACK, R. W. Designing effective performance-measurement systems under the government performance and results act of 1993. Public Administration Review, v. 56, n. 4, p. 348-358, 1996.

LAGIOIA, U. C. T et al. A gestão por processos gera melhoria de qualidade e redução de custos: o caso da unidade de ortopedia e traumatologia do Hospital das Clínicas da Universidade Federal de Pernambuco. Revista de Contabilidade e Finanças, v. 19, n. 48, p. 77-90, 2008.

LEONE, George Sebastião Guerra. Custos, planejamento, implantação e controle. 3. ed. São Paulo: Atlas, 2000.

LUQUE, C. A. et al. O processo orçamentário e a apuração de custos de produtos e serviços no setor público do Brasil. Revista do Serviço Público, v. 59, n. 3, p. 309$331,2008$. 
MACHADO, Nelson. Sistema de Informação de Custo: diretrizes para integração ao orçamento público e à contabilidade governamental. Brasília: Enap, 2005.

MACHADO JR., José Teixeira; REIS, Heraldo da Costa. A Lei 4.320 comentada. 30. ed. Rio de Janeiro: Ibam, 2000/2001.

MARTINS, Eliseu. Contabilidade de custos. 9. ed. São Paulo: Atlas, 2003.

MAUSS, César Volnei; SOUZA, Marcos Antonio de. Gestão de custos aplicada ao setor público. Modelo para mensuração e análise da eficiência e eficácia governamental. São Paulo: Atlas, 2008.

MIRANDA, G. J. et al. Custeio ABC no ambiente hospitalar: um estudo nos hospitais universitários e de ensino brasileiros. Revista de Contabilidade e Finanças, v. 18, n. 44, p. 33-43, 2007.

MOURA, José Flávio de Melo. O sistema de contabilidade do governo federal na mensuração dos custos dos programas de governo e das unidades gestoras. 2003. Dissertação (Mestrado) - Universidade de Brasília.

SHANK, John K.; GOVINDARAJAN, Vijay. Estrategic cost management - the new tool for competitive advantage. New York: The Free Press, 1993.

SILVA, César Augusto Tibúrcio (Org.). Custos no serviço público. Brasília, 2004.

SILVA, Lino Martins da. Contribuição ao estudo para implantação de sistema de custos na administração pública. Brasília: Esaf, 1997.

. Contabilidade governamental - um enfoque administrativo. 5. ed. São Paulo: Atlas, 2002. 